\title{
PRÁTICA REFLEXIVA ENTRE PROFESSORES: UMA ABORDAGEM COLABORATIVA NA FORMAÇÃO DE PROFESSORES DE INGLÊS ${ }^{1}$
}

\author{
Ivone Santana ${ }^{2}$ \\ Telma Nunes Gimenez ${ }^{3}$
}

\begin{abstract}
RESUMO
O objetivo desta pesquisa foi identificar evidências de reflexão por um grupo de formadores de professores de inglês, atuantes em um curso de Letras, por meio da análise dos padrões interacionais durante quatro reuniões de trabalho. Os dados foram coletados por meio de gravações em áudio e analisados em sociogramas, para estabelecimento do clima interpessoal, bem como de evidências de reflexão caracterizada pela apresentação de problemas, sugestões de soluções e análise de suas conseqüências. Os resultados indicaram a liderança de um dos membros em um clima de cooperação. Todas as reuniões envolveram colocações de problemas e possíveis soluções, demonstrando a possibilidade de se refletir em reuniões de trabalho.
\end{abstract}

PALAVRAS-CHAVE: reflexão, reuniões de trabalho, formadores de professores.

\section{INTRODUÇÃO}

A formação de professores de línguas estrangeiras tem sido guiada, nos últimos anos, pela abordagem reflexiva. Esta compreende, fundamentalmente, uma rejeição de modelos de aplicação de teorias, ou “racionalidade técnica”. Na abordagem reflexiva a aprendizagem com a própria experiência é componente importante no desenvolvimento do conhecimento sobre ensino. Referenciais oriundos da teoria sócio-cultural têm se tornado relevantes para explicar de que modo professores aprendem de modo “situado". Entretanto, são ainda poucos os estudos que se concentram no modo como formadores de professores refletem sobre suas práticas e como aprendem colaborativamente. Este projeto teve como objetivo analisar uma possível instância desse aprendizado, isto é, transcrições de reuniões de educadores envolvidos com a disciplina Prática de Ensino de Língua Inglesa, de modo a detectar os padrões interacionais assumidos e o papel dos interagentes na construção de novos conhecimentos sobre formação de professores de inglês em estágios iniciais.

Tem sido comumente aceito que professores trabalham de modo isolado. Freeman \& Hawkins (2004, p. 3 ) colocam:

\footnotetext{
${ }^{1}$ Agradecemos ao CNPq (Proc. 305564/2005-6) o apoio para realização desta pesquisa.

${ }^{2}$ Graduada em Letras Anglo-Portuguesas.

${ }^{3}$ Professora Associada do Departamento de Letras Estrangeiras Modernas, UEL.
} 
Opportunities to exchange ideas or discuss with colleagues what they know or believe are rare and valued. Most professional development fails to counteract such isolation. The chance to think together, in disciplined ways, through collaborative exploration, reflection and conversation is key. ${ }^{4}$

Para aquele autor, a concepção de melhores ferramentas que possam levar a um desenvolvimento (i.e. aprendizagem) envolve a estruturação das interações entre educadores em ambientes de trabalho. Da mesma forma, Pugach \& Johnson (1990) propõem que a interação seja estruturada (chamada de colaboração entre pares), em que um dos participantes assume o papel de "iniciador” (initiator) e o outro o de facilitador, ao guiar seu parceiro na utilização da estratégia adequada. De acordo com aqueles autores, os 4 passos que tornam possível a colaboração envolvem:

1. identificação do problema através de auto-questionamento em uma situação de aprendizagem guiada que permita redefiní-lo;

2. resumo do problema redefinido;

3. geração de possíveis soluções e predição do que pode ocorrer caso sejam adotadas;

4. consideração de várias maneiras de avaliar a eficácia da solução escolhida.

A proposta da reflexão no desenvolvimento profissional continuado tem sido bem aceita nos meios acadêmicos, embora com uma variedade enorme de entendimentos. Estudos têm enfatizado que o processo reflexivo acontece em ambientes colaborativos nos quais o outro representa um papel fundamental na condução de questionamentos que podem levar à reflexão de práticas educativas. Entretanto, embora haja uma literatura substancial no campo da formação de professores, é menos comum encontrar trabalhos que tratem do modo como formadores de professores refletem e aprendem colaborativamente.

Assim, sob a diversidade de entendimentos sobre reflexão podem ser encontradas diferentes formas de promovê-la. Considerando a importância das ferramentas para o desenvolvimento da aprendizagem dos próprios envolvidos com a formação de professores, este projeto buscou analisar de que modo um grupo de formadoras de professores de inglês em um curso de Letras conversavam em reuniões da área e de que modo essas conversas refletiam suas preocupações com o objetivo de seu ensino, i.e., a preparação de futuros

\footnotetext{
${ }^{4}$ Oportunidades para troca de idéias e discussões com colegas sobre o que sabem ou acreditam são raras e valiosas. Na maioria dos casos as formas de desenvolvimento profissional adotadas falham em se contrapor a tal isolamento. A oportunidade de pensar coletivamente, de modo disciplinado, por meio da exploração colaborativa, reflexão e conversa é fundamental.
} 
professores. Adicionalmente, o propósito foi verificar até que ponto essas reuniões não estruturadas poderiam funcionar como ferramentas eficazes no processo de desenvolvimento profissional daquele grupo.

A conversa entre profissionais pode ser considerada uma ferramenta importante no processo de desenvolvimento profissional, na medida em que contiver elementos de reflexão. Esta pode ser entendida como a análise crítica de um conjunto de pressupostos (compartilhados ou não), com propostas de alternativas para os problemas detectados na prática.

A importância de atividades dessa natureza é ressaltada por autores como Hawkins e Irujo ( 2004) e Farrell (1999). Este último descreve estudo no qual um grupo de formadores se reuniram para refletir sobre suas práticas. Essas reuniões foram gravadas e, juntamente com diários do organizador do grupo e dos próprios participantes, foram realizadas análises para se identificar os padrões interacionais adotados, seguindo procedimento da Análise da Conversação. Foram desenhados sociogramas de interação de grupo para cada uma das reuniões. Assim como Farrell (1999), o objetivo deste trabalho foi verificar como as conversas em reuniões de área criaram ou não oportunidades para os participantes refletirem sobre seu trabalho, e por esse motivo, utilizamos alguns dos procedimentos relatados naquele estudo e explicados a seguir.

\section{MATERIAL E MÉTODOS}

Os dados foram coletados em quatro reuniões realizadas entre dezembro de 2002 e Junho de 2004, das quais participaram, ao todo, oito formadoras do curso de Letras AngloPortuguesas encarregadas da disciplina - Prática de Ensino de Língua Inglesa, (identificadas neste trabalho como professoras - T1, T2, T3, T4, T5, T6, T7 e T8), embora nem todas as reuniões tenham contado com a presença de todas. As análises demonstrarão mais claramente quais participaram de quais reuniões.

As quatro reuniões foram realizadas nas seguintes datas:

$$
\begin{aligned}
& 1-12 / 12 / 2002 \\
& 2-05 / 06 / 2003 \\
& 3-12 / 12 / 2003 \\
& 4-06 / 02 / 2004
\end{aligned}
$$


A primeira reunião envolveu 5 formadoras e teve como foco uma avaliação do andamento do estágio. Foram comentadas questões administrativas, a relação com a escola como campo de estágio e com o professor colaborador, o papel da supervisora no encaminhamento de práticas a serem desenvolvidas pelos alunos-professores. Foram identificados problemas e propostas, além de soluções de encaminhamento.

A segunda reunião caracterizou-se de modo diferenciado, por se constituir como um grupo focal em que o tema era a sistematização da reflexão. Participaram 4 formadoras. Foram problematizadas as relações com professores colaboradores e a assimetria entre professores universitários e professores colaboradores. A questão da sustentabilidade da reflexão também foi questionada. Foram apresentadas propostas de encaminhamento dos problemas levantados.

A terceira reunião contou com 5 formadoras e teve como foco o planejamento do ano seguinte. Foram também identificados alguns possíveis problemas e propostas para sua solução.

A quarta reunião contou com 6 formadoras e tratou da retomada do planejamento e integração entre os $2^{\circ}$ s., $3^{\circ}$.s e $4^{\circ}$ s anos do curso.

As reuniões foram gravadas em áudio e transcritas. Os dados foram analisados seguindo a metodologia proposta por Farrell (1999) com relação ao sociograma, que é desenhado a partir das seguintes indicações:

1. Primeiramente é feito um quadrado para cada membro indicando onde estão sentados.

2. É desenhada uma seta para cada fala daquele membro em direção à pessoa com a qual falou e o número de comentários/perguntas são anotados na linha com a seta indicando a direção do comentário.

3. Se o comentário for para o grupo ao invés de um indivíduo específico, a seta é apontada para fora.

Os sociogramas indicam os diferentes níveis de envolvimento dos participantes nas reuniões. Na pesquisa daquele autor, o clima interpessoal criado foi avaliado de acordo com 5 perguntas:

1.Quem recebeu mais comunicação?

2.Quem quase não se comunicou? 


\section{Quem estava ausente?}

4.Quem fez mais questionamentos para o grupo?

5.Quem falou com quem?

Neste estudo, além da identificação do clima interpessoal, trazemos também excertos das reuniões que demonstram, conforme postulado por Pugach \& Johnson (op. cit), indícios de reflexão. Em função de limitações de espaço as diversas etapas de cada reunião são sintetizadas em comentários sobre os passos seguidos pelo grupo.

\section{RESULTADOS}

O quadro abaixo nos fornece uma síntese com as respostas às 5 perguntas acima.

\begin{tabular}{|l|c|c|c|c|}
\hline \multicolumn{4}{|c|}{ REUNIÕES } \\
\hline \multicolumn{1}{|c|}{ PERGUNTAS } & $\mathbf{1}$ & $\mathbf{2}$ & $\mathbf{3}$ & $\mathbf{4}$ \\
\hline Quem recebeu mais comunicação? & $\mathrm{T} 1+\mathrm{T} 6+\mathrm{T} 4$ & $\mathrm{~T} 1$ & $\mathrm{~T} 1+\mathrm{T} 2$ & $\mathrm{~T} 1$ \\
\hline Quem quase não falou? & $\mathrm{T} 5$ & $\mathrm{~T} 2$ & $\mathrm{~T} 5$ & $\mathrm{~T} 5$ \\
\hline Quem estava ausente? & $\mathrm{T} 2+\mathrm{T} 3+\mathrm{T} 8$ & $\mathrm{~T} 3+\mathrm{T} 5+\mathrm{T} 7+\mathrm{T} 8$ & $\mathrm{~T} 3+\mathrm{T} 7$ & $\mathrm{~T} 4+\mathrm{T} 8$ \\
\hline Quem fez mais questionamentos para o grupo? & $\mathrm{T} 6$ & $\mathrm{~T} 1$ & $\mathrm{~T} 1$ & $\mathrm{~T} 1$ \\
\hline Quem mais falou com quem? & T1com T4 & T1com T6 & T1 comT4 & T1 comT6 \\
\hline
\end{tabular}

Em uma perspectiva global, observou-se o papel de uma líder potencial no grupo, T1, com 11 turnos na reunião 2, 89 na reunião 3 e 54 na reunião 4. Essa também foi uma das participantes que mais recebeu comunicação nas reuniões. A participante que menos se comunicou, T5 foi a mesma em quase todas as reuniões. Os pares de comunicação se mantiveram de forma alternada; primeira reunãoT1+T4 (15/11), segunda reuniãoT1+T6 (5/3),terceira reunião T1+T4(32/55), e Quarta reunião T1+T6 (34/45). O sociograma da Figura 1 ilustra a interação entre as participantes na primeira reunião. 
Figura 1 - Sócio-grama da primeira reunião

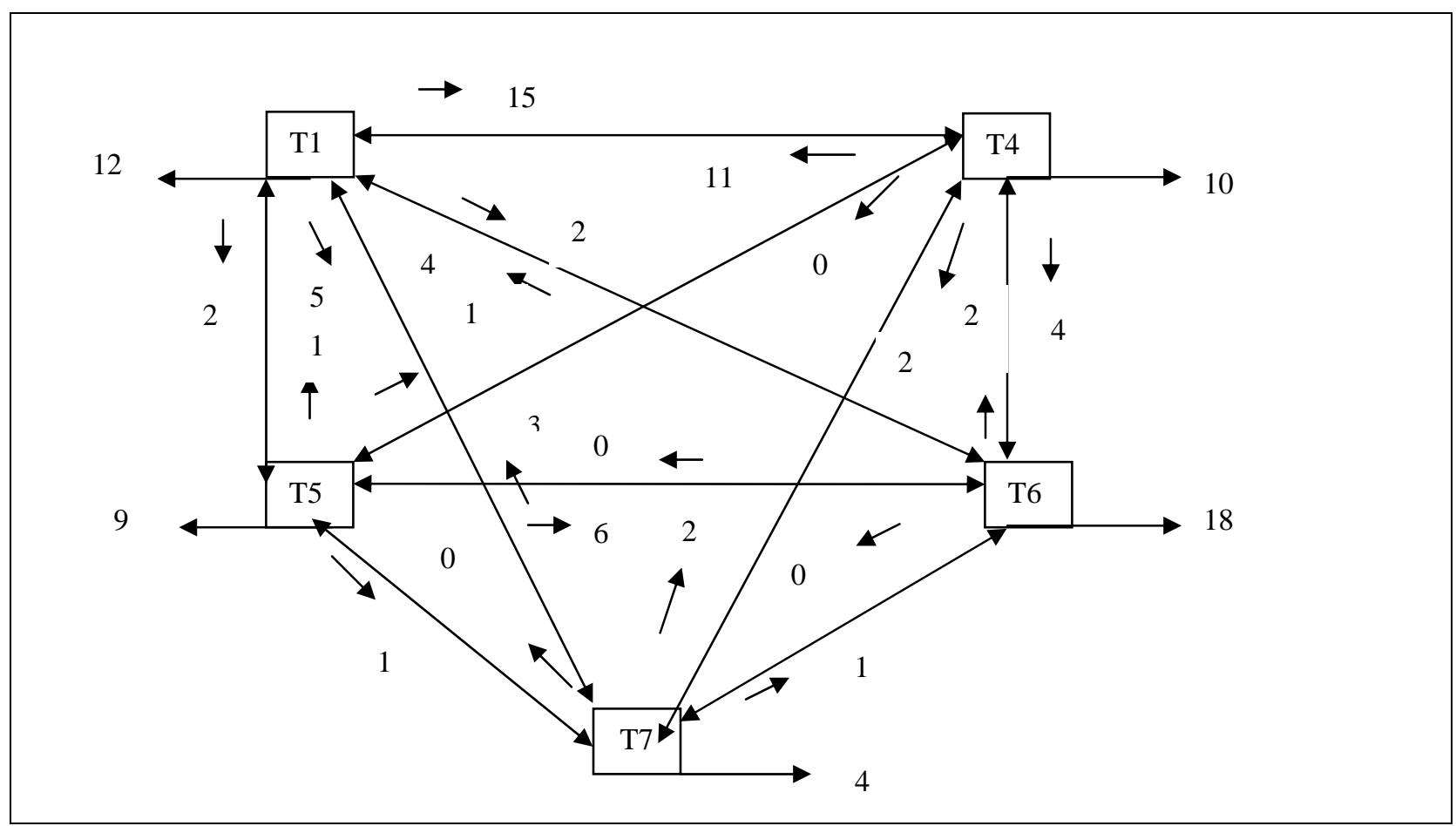

Na figura 1, T6 surge como um líder potencial com (18) perguntas ao grupo. Os outros participantes aparecem com um número menor de perguntas. T1,T4,T6 são os que recebem mais comunicação. De acordo com o esboço acima, vê-se que T5 foi quem menos se comunicou com o grupo. Contudo, de uma forma geral, todos colaboraram para o bom andamento da reunião, portanto não foi percebido nenhum tipo de barreira que pudesse ter inibido a participação efetiva dos membros do grupo.

Um dos momentos propiciadores de reflexão pode ser visto abaixo.

\section{Episódio 1 - primeira reunião}

\section{Colocação do problema}

T5-Essa coisa da gramática está muito arraigada

T7-Olha, eu vou relatar uma turma minha de quarto ano noturno, que foram meus alunos no segundo ano em lingüística aplicada e meus alunos no terceiro ano. Eles fizeram parte daquele plano de trabalho só com avaliação de material didático. Parte desses alunos, porque no quarto ano eu peguei a turma toda, alguns não foram meus alunos no terceiro ano, mas foram meus alunos no segundo ano com lingüística aplicada e eu me senti, extremamente, frustrada porque realmente a idéia de PCN não ficou nada. Eu me lembro, no segundo ano, eles trabalharam comigo os PCNs e fizemos planos de unidade em cima de temas transversais....Aí no terceiro ano, eu fiquei com 10 desses 20 e poucos que eu tenho;...trabalhamos análise de material didático em cima da proposta de PCN e quando chegou no quarto ano que eu esperava que eles elaborassem as suas aulas os seus planos de unidade, eu fiquei extremamente frustrada, porque eles só conseguiam pensar mesmo em aula de gramática. 


\section{Proposta de solução}

T1-Eu acho que está, ... me parece que está se chegando a um consenso,. a necessidade de um direcionamento; porque o que T4 está fazendo é um direcionamento. Olha, nós vamos trabalhar com gênero; escolhi isso.. Vocês podem escolher qual gênero, a gente decide o que vai ser e tal; mas vai ser isso. Eu, no ano passado e no ano retrasado, resolvi trabalhar com uma organização temática; então a minha decisão foi - vai ser uma organização temática. Nós vamos ter uma proposta de trabalho comum e aí é a única forma de garantir que os alunos do terceiro vão chegar no quarto com a mesma convenção; porque senão cada um de nós vai ter um enfoque e dar esse enfoque no terceiro ano e aí ? E se ele pega um professor no quarto ano, que tem outro enfoque? Vai ter que aprender tudo de novo? Seria bom, se a gente tivesse um enfoque comum no terceiro ano. Digamos, vamos trabalhar gêneros textuais,...então o aluno tem que sair do terceiro ano sabendo descrever e propor material didático para os gêneros tais. Isso fica sendo o objetivo comum nosso, ou a gente deixa meio que solto para cada um decidir o que fazer? Eu acho que isso tem que passar mesmo por um processo contínuo, por esse processo aí de formação.

A partir da definição do problema (alunos-professores centrados no ensino de gramática) este foi sendo redefinido (necessidade de proposta comum) para uma solução (dar um direcionamento comum). Esse momento de troca de experiências é relevante no processo reflexivo, pois é quando o formador vê onde está o problema e discorre sobre ele, aumentando assim, as chances de se chegar ao uma outra visão do assunto, ou a uma possível mudança.

\section{Figura 2 - Sociograma da segunda reunião}

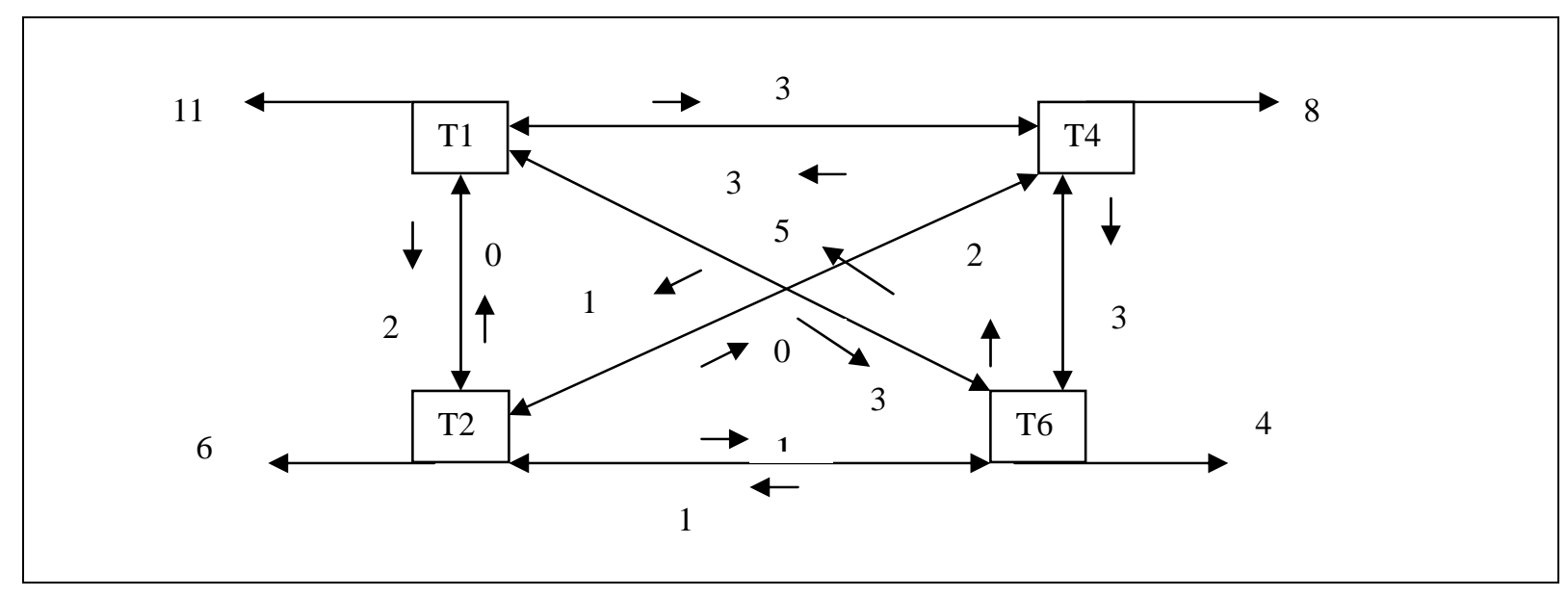

Na figura 2 pode-se visualizar a interação no segundo encontro, caracterizado como um grupo focal. O esboço acima mostra a liderança de T1 que faz questionamentos ao grupo, sendo também, o que mais recebe comunicação. Os outros participantes também fazem questionamento ao grupo, só que em menor escala. Quanto ao pares de comunicação T1+T6(3/5) se destacam. Aqui, (T2) é o participante que menos se comunicou.

Neste encontro, o líder potencial faz questionamento ao grupo com objetivo de direcionar a conversa a aspectos específicos da reunião como a abordagem utilizada pelos formadores. 
Quanto ao assunto em discussão, pode-se dizer que foi diferenciado; visto que se tratava de um grupo focal, cujo objetivo era fazer uma pesquisa sobre abordagem reflexiva utilizada pelas formadoras na orientação de estágio supervisionado. Neste contexto, os tópicos mais comentados foram a definição de reflexão, a sistematização da reflexão, a função da observação e impacto, como se pode ver abaixo.

\section{Episódio 2}

\section{Colocação do problema}

T1- Eu tenho algumas dúvidas com relação a essa sistematização. Eu acho que a gente tem , como vocês falaram um roteiro de observação e um roteiro para elaboração do relatório da observação, que são dois instrumentos então que a gente usa. Quando a gente ao mesmo tempo delimita, porque não dá para trabalhar com a reflexão de um modo muito abstrato, ela precisa ter uma instância concreta de realização, ela pode estar num formato mais fechado, que eu acho que é o que Smyth propõe, ou ela poderia estar num formato mais aberto [...]Eu acho que essa é uma etapa, se a gente está pensando na reflexão como uma forma de levar à autonomia, talvez a própria pessoa deveria definir o que ela quer ou não fazer com o resultado desse processo, não necessariamente que ela tenha que fazer algo diferente ou de novo. Essas perguntas ou essas reconstruções deveriam ser da própria pessoa, não guiadas, mas surgir do próprio processo de estar pensando essa prática com base em alguns parâmetros, alguns referenciais, porque eu acho que a reflexão talvez seja isso, a gente ter a possibilidade de olhar para essa prática voltando para,alguns referenciais que pode ser a teoria, ou seja lá o que for; o que eu quero fazer com o resultado disso deveria estar nas minhas mãos. (...) Acho que há alguns pressupostos, como todos nós operamos com pressupostos, mas os pressupostos da fase do reconstruir eu acho que estão muito limitantes, esta muito fechado, seria uma etapa talvez desnecessária. Ela poderia até acontecer como conseqüência das anteriores, mas não necessariamente acontecer assim. Por isso, que os alunos têm algumas dificuldades mesmo, de partir para essa etapa, por que se a pergunta for colocada: o que você faria de diferente? Aí, "agora, tem que fazer diferente, agora não sei como que é que eu faço diferente, eu não desenvolvi ainda conhecimento suficiente"T4- É aquilo que eu falei se ele chegar à conclusão de que aquela situação deveria ser feita daquele jeito mesmo, talvez ele não contemple à expectativa do orientador

T1-Talvez, essa reconstrução não seja uma reconstrução nas mesmas bases? O que é então que a gente está querendo dizer com reconstruir? É fazer diferente ou é fazer o mesmo caminho?

\section{Proposta de solução}

T4-Acho que a gente talvez pudesse pegar os relatórios dos alunos que foram para essas escolas (...) e talvez a gente pudesse eleger alguns contextos, ou talvez ir lá e conversar com esses professores para fazer uma proposta de um trabalho com eles.

O episódio ilustra a redefinição do problema da observação e sua função para futuros professores e professores colaboradores. O autor citado pelas formadoras, Smyth (1992), propõe que a reflexão crítica pode ser obtida a partir de quatro ações distintas pelas quais o professor poderia desenvolver a reflexão crítica: descrever, informar, confrontar e reconstruir, sendo este utilizado pelas formadoras como forma de levar os alunos a sistematizarem sua reflexão. Ao questionar a etapa de reconstrução (o que é então que a gente está querendo dizer com reconstruir?), o problema é redefinido como sendo a manutenção da hierarquia na 
realização do estágio, com pouco espaço para o professor colaborador dizer o que espera desse tipo de interação ${ }^{5}$. Sua solução envolve uma nova forma de relacionamento com as escolas (talvez ir lá e conversar com esses professores para fazer uma proposta de trabalho com eles).

\section{Sociograma da terceira reunião}

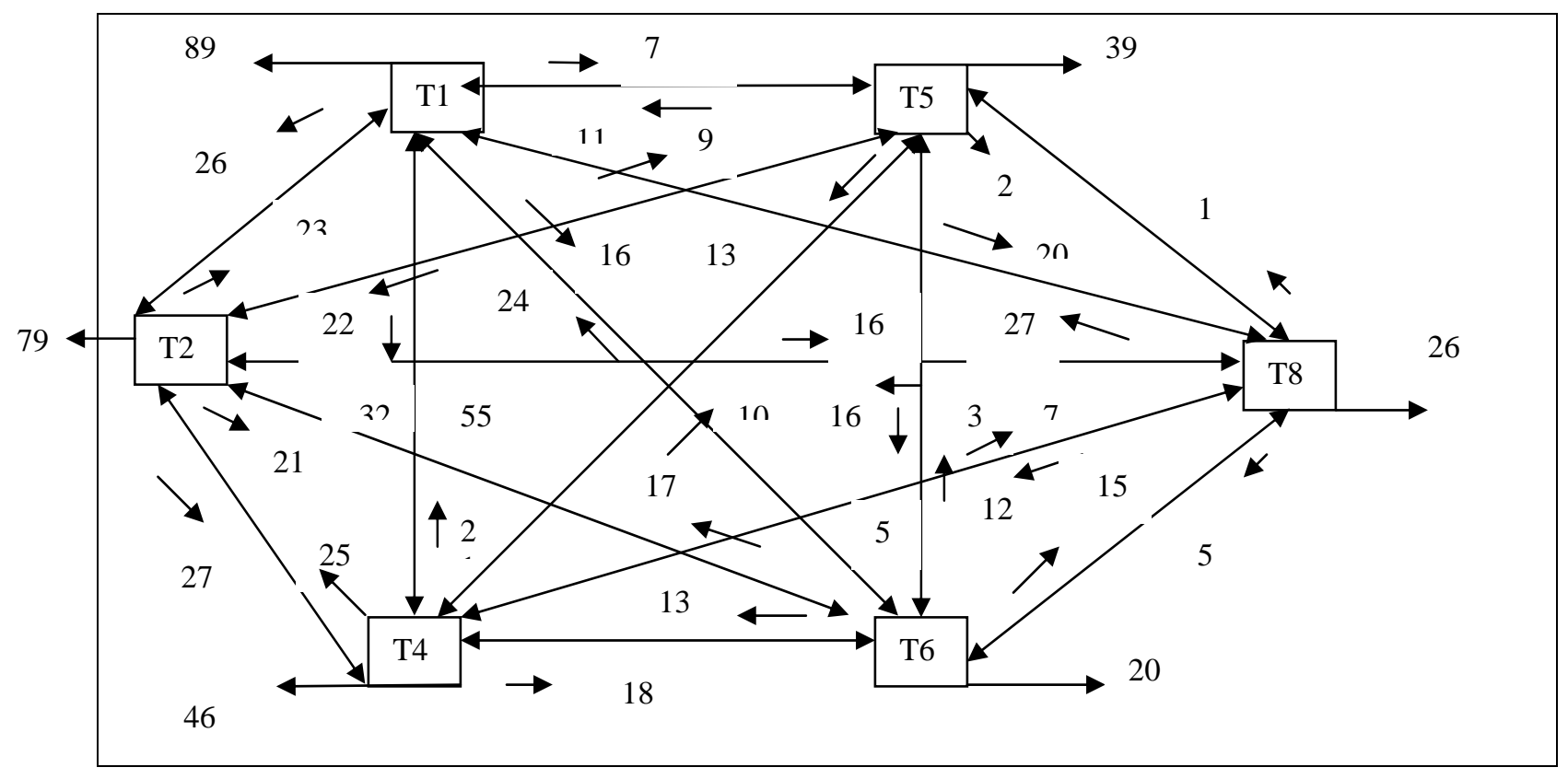

O sociograma da terceira reunião mostra a predominância de questões administrativas, com 54.57\% dos turnos direcionados para a distribuição de alunos por supervisor e escola no próximo ano. Embora este tenha sido o foco, os papéis não sofreram alterações significativas: T1 continua a ser a líder com (89) perguntas ao grupo, também é quem recebe mais comunicação, junto com T2. Outros também recebem comunicação. Nota-se que T2, no segundo encontro, foi o participante que menos se comunicou, agora lidera junto com T1. Aqui T5 ainda permanece como o participante que se comunica pouco.

No episódio a seguir, a prática de atribuir diferentes contextos para observação é objeto de análise pelo grupo, assim como as tarefas solicitadas aos alunos do $4^{\circ}$ ano e sua eficácia (e.g. leitura de textos).

\footnotetext{
${ }^{5}$ Estes trechos não foram reproduzidos em função de limites de espaço.
} 


\section{Episodio 3}

\section{Colocação do problema}

T1-Eu acho T4, que é importante talvez eles terem algum tipo de experiência de regência no $3^{\circ}$ ano, mas em um ambiente mais protegido.

T4-É

T`1- Eles não, quando eles entram mesmo no $4^{\circ}$, eles entram dentro da sala por mais que você tenha trabalhado com esse planejamento, você não tem passo a passo e tudo o que eles vão dizer, eles escrevem errado, eles falam errado...

T4-Eles falam errado...

T1- Eles ensinam errado e você fica lá assistindo naquela posição vou lá corrijo, ou vou lá e não corrijo? T8- Isso você não pode, você vai ou não vai né..

T1-A menina me escreve no quadro byebye com by, me escreve ....gone (gon) espera ai, então não sei como você lida com estas questões ...

T5- Eu acho muito importante sim, o ambiente protegido para quem vai dar aula.

\section{Proposta de solução}

T5-Eu acho que iniciar neste contexto mais protegido é importante; por que eu tenho alunos no $4^{\circ}$ que têm problemas muito sérios de pronúncia lingüística, então é um espaço para eles experimentarem um pouco mais.

T2-Eu, particularmente, acho que tem que pensar no desenho disso; se eu tivesse um espaço para estar lá junto com eles; eu gostaria muito de estar nessa posição, não na sala necessariamente. Eu acho que não sei ainda como a T8 está fazendo. Eu acho que demanda tempo .Não sei se eu T2, sem nenhum projeto, estaria preparada para estar lá na sala com o professor regente eu os alunos; mas não me custa dar esse nome; num espaço que eu pudesse atuar junto com esses alunos né, com esse grupo eu teria muito interesse em fazer, porque eu acho que ai a gente poderia falar "é assim” “ não é ”, estar participando, talvez fosse uma questão de desenho mesmo; como isso vai acontecer, com que freqüência, se teria que ser através de um projeto.

O problema, conceituado como falta de preparo dos alunos para entrar em sala de aula é discutido e a solução proposta em termos de "espaços protegidos” para a regência ainda no terceiro ano. Geralmente, a regência é realizada apenas no $4^{\circ}$ ano. Neste caso, a solução é sugerida em função de experiências já realizadas por outros colegas que, por meio de projetos, conseguem amenizar o problema de espaços “desprotegidos”. 


\section{Sociograma da quarta reunião}

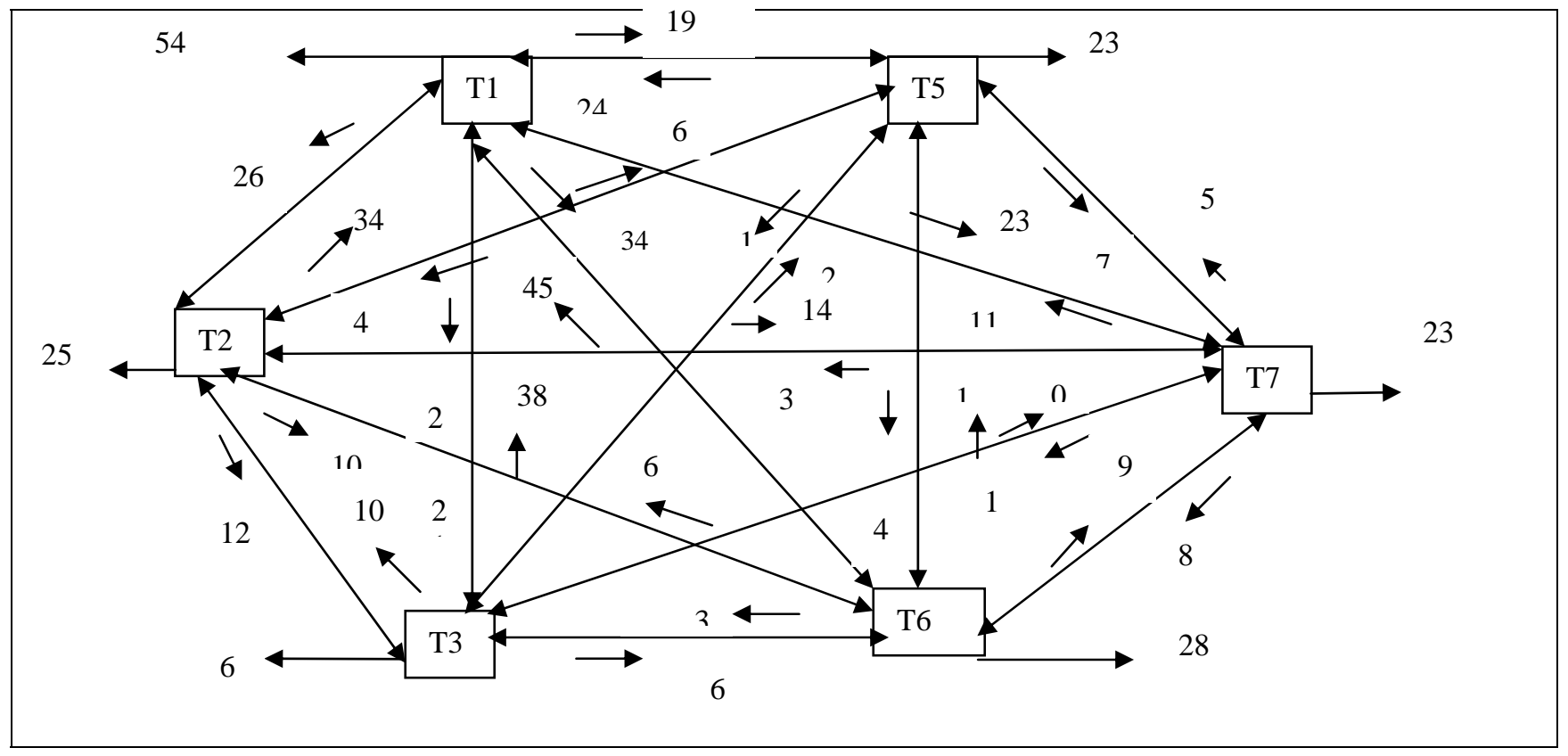

Esta reunião tratou do planejamento do semestre, buscando a integração da disciplina de lingüística aplicada, oferecida no segundo ano e sob responsabilidade de nova professora, e as práticas de ensino de $3^{\circ}$ e $4^{\circ}$ ano. Problemas relativos à falta de embasamento dos alunos para execução da prática de ensino foram discutidos, assim como quais referenciais teóricos poderiam ser úteis naquela etapa do curso.

Apesar de ter havido uma mudança no foco, os papéis continuaram semelhantes:T1 permanece como o líder com (54) perguntas ao grupo. T1 ainda se mantém como o participante que mais recebe comunicação. T5 continua sendo a que menos se comunicou.

\section{Episodio 4}

\section{Colocação do problema}

T1-A idéia é que, os professores que estão pegando os alunos então no $3^{\circ}$, principalmente, estão sentindo que os alunos estão, assim um pouco.... é pouco sólidos...

T3-Despreparados

T1-Parece que faltam a eles algumas noções que deveriam ter sido trabalhadas anteriormente. É, não necessariamente, porque não foi dado, mas talvez a gente não tenha pensado.

T3-Antes do $3^{\circ}$. ano, a única que vai tratar de metodologia de ensino é a Lingüística Aplicada.

T1-É, na verdade, ela chama Lingüística Aplicada, e a LA é uma coisa bem mais ampla.

T3-É, eu estava lendo, ela não está só voltada para o ensino.

T1-Na verdade, é Lingüística Aplicada, mas o enfoque é o ensino.

T6-E uma outra coisa também é pensar assim: o peso que tem o quando deve ocupar no programa o estudo dos Parâmetros. Porque eu acho também o seguinte: tem que pensar que isso é uma coisa que pode ser que daqui a dois anos não esteja mais valendo. Então, não é eu acho que não é assim: o propósito não é eles conhecerem para quando eles tiverem que dar aulas isso vai ter que orientar o professor, o que eles vão fazer; mas para ter uma idéia de que tem isso hoje orientando o ensino. 


\section{Proposta de solução}

T2-Então, eu acho que as leituras que a gente foi fazendo, acho que de acordo com o programa ali, eram leituras que acabavam se sobrepondo à leitura dos Parâmetros. É isso que eu estou dizendo né, não fazer : agora é o momento dos Parâmetros; mas analisar várias leituras sobre interação e os Parâmetros serem uma terceira leitura, por exemplo, você não fala leia sobre isso, entendeu? É uma outra - porque ela acaba - muitas coisas acabam se sobrepondo.

T3-É uma tarefa talvez consultar os Parâmetros para saber como aquele assunto é tratado.

T2-Para ver como aquele assunto é tratado e como você tratou ...

T3-Os Parâmetros complementariam sobre leitura, sobre interação...

T2- Mas no momento do assunto entendeu? não no momento Parâmetro. É isso que - não deslocado lá, agora vai estudar os Parâmetros.

No episódio acima, as falas se concentram na relevância que se deve ou não dar aos PCNs. O problema foi conceituado como sendo o programa para a disciplina de Lingüística Aplicada e sua relação com os parâmetros curriculares. Após várias intervenções, chegou-se ao consenso de que estes apenas orientariam os tópicos e não seriam o único guia para a disciplina (os Parâmetros complementariam).

Em meio a análises quantitativa e qualitativa dos dados, observa-se que, as reuniões proporcionaram oportunidades para redefinição de problemas e encaminhamento de soluções, caracterizando um diálogo colaborativo, de acordo com a visão de Pugach \& Johnson (1990).

Houve predominância de participação de uma das professoras, enquanto que outra se comunicou menos. Isto, no entanto, não significou que as suas participações nas reuniões não tenham sido relevantes. Pode-se notar que T2, apesar de ter sido a participante que menos se comunicou na segunda reunião, na terceira e quarta reuniões foi a participante que propôs soluções para os problemas levantados. Essa mesma consideração pode ser aplicada a T5 que foi, predominantemente, a participante que menos tomou o turno em três das reuniões. Contudo, é uma das participantes que levantou questões significativas na primeira reunião. Dessa forma, pode-se dizer que uma análise apenas quantitativa não seria a mais indicada para um estudo aprofundado sobre a interação entre as formadoras, e sim, uma analise qualitativa, que observaria a relevância, a qualidade da interação e não apenas a quantidade desta.

Diferentemente do estudo de Farrell (op.cit), não encontramos evidências de “mecanismos de defesa” nas falas analisadas. Provavelmente em virtude de o grupo ser constituído de pessoas da mesma instituição com história de relacionamento profissional e pessoal, o clima interpessoal se revelou favorável a um processo reflexivo, conforme caracterizado por Pugach \& Johnson (op.cit). 


\section{CONSIDERAÇÕES FINAIS}

Neste estudo, foram observados indícios de reflexão: a identificação de problemas através de indagações sugere um desejo de compartilhar conhecimentos e repensar práticas; aspecto que possibilita às participantes redefinir esses problemas e tentar chegar a soluções, colocadas em forma de alternativas. Consequências das soluções propostas também são consideradas. Isto revela que a reflexão pode ocorrer mesmo em reuniões não estruturadas; desde que os participantes tenham oportunidade de expor os problemas encontrados na prática profissional e submeter-se à opinião do outro, na tentativa de encontrar possíveis resoluções para os problemas. Dessa forma, este estudo proporcionou uma visão de como os formadores podem estar refletindo em suas práticas profissionais de forma colaborativa.

\section{REFERÊNCIAS}

FARRELL, T. Teachers talking about teaching: creating conditions for reflection. TESL-EJ, v. 4, n.2,1999. Disponível em < http://tesl-ej.org/ej14/a1.html>.

FREEMAN, D. \& HAWKINS, M. Collaborative reflection as critical practice in teacher education. In: HAWKINS M.; IRUJO, S (orgs). Collaborative Conversations among language teacher educators. Alexandria: TESOL, 2004.

HAWKINS M. IRUJO, S (orgs). Collaborative Conversations among language teacher educators. Alexandria: TESOL,2004.

PUGACH. M. C. \& JOHNSON, L. J. Developing Reflective Practice Through Structured Dialogue. In: CLIFT, RT; HOUSTON, WR; PUGACH, MC. (eds).Encouraging Reflective Practice in Education. New York: Teachers College Press,1990.

SMYTH, J. Teacher's work and the politics of reflection. American Educational Research Journal. v. 29, n. 2, 1992, p. 267-300. 